\title{
Application of Matrix Method of Presenting Semantic Relations in Didactic Practice ${ }^{*}$
}

\author{
Eva Leláková, Marta Lacková \\ University of Žilina, Žilina, Slovakia
}

\begin{abstract}
The present paper offers the results of the linguistic research dealing with the theory and practice of lexico-semantic fields interconnected with mathematical (matrix, set, and weight) theories. Matrix of the observed lexico-semantic field represents semantics of the synonymic row of the noun happiness in a formalized way and with its help, all the semantic interconnections between all the members of the lexical stock under study can be studied and noted down in a transparent way. Matrix analysis has its irreplaceable place and application not only in lexicographic but also in didactic practice. Special componential grids (= matrices) can find their application as practical teaching aids in the process of vocabulary teaching, learning, and acquisition.
\end{abstract}

Keywords: matrix, semantic relations and interconnections, teaching aid, vocabulary acquisition

\section{Introduction}

Language as a system of linguistic units used in a particular language is the best represented in monolingual explanatory dictionaries. They—as unlimited sources of information—can be objects of linguistic activity, means of promoting vocabulary acquisition, instruments of research works, the starting points for deducing lexicographic theories and the reference and learning aids for foreign language teachers and learners, translators, interpreters, scientists - in fact for all the general public. However, after a complex and deeper insight into their system of organisation, we realize that the lexical information they contain is not complete and sufficient. The reason lies in the fact that it is technically, logically, and spatially impossible to record all the semantic relationships and connections between the words and to capture the "depth" of all the vocabulary in the conventional dictionaries.

Non-native language learners in their learning process must identify new words, recall them, work out their relationships with other words and with a real world, and learn to use them appropriately to avoid a flat, boring and inadequate speech. As the semantic information found in alphabetical dictionaries misses conceptual links, it is not satisfactory for building up their mental lexicon. They subconsciously gather together all the words that have related senses and store them in their own "ploughed" semantic fields (Crystal, 2007). A network of associations made within these fields makes their learning process more complex and efficient and markedly improves the depth of their lexical knowledge.

\footnotetext{
* This paper has been written with the support of European Social Fund, project innovation and internationalization of education - instruments to increase the quality of the University of Žilina in the European educational area. ITMS code 26110230079. Modern Education for the Knowledge Society/Project is funded by EU.

Eva Leláková, Ph.D., Department of English Language and Literature, Faculty of Humanities, University of Žilina in Žilina.

Marta Lacková, Ph.D., Department of English Language and Literature, Faculty of Humanities, University of Žilina in Žilina.
} 
The present research proceeds from the assumption that semantic links are very important for the storage of language material, and that also other scientifically verified alternatives of conventional dictionaries should be offered to language users for their better orientation in the language system and especially for providing them with even subtle, nearly elusive meaning differences of semantically related words. In the research, a lexico-semantic field as an organizing principle for the study of words and idioms is used.

\section{Matrix of Lexico-Semantic Field of the Nouns Denoting Happiness in English}

All the defenders of the field theory agree that the vocabulary of the specific language is a well-integrated system of lexemes and it is organized into a great amount of lexical sets on the basis of common elements. Within each field/group/frame or paradigm, lexemes interrelate and define each other in specific ways. If we understand a lexical meaning of the word as a reflective category and if the reflection of reality in the human mind is characterized by the form of a lexeme, if the work with semantic components of the lexical meaning is done within a language system, depiction of relations among individual units of language becomes very effective and precise when a componential grid (matrix) adapted for this specific aim is used.

A matrix, in general, is a rectangular array of objects with a finite or infinite number of lines and columns (Karris, 2004). There are two intersecting dimensions in it represented by horizontal and vertical axes. In our case, a lexical stock with a finite number of lexical units (i.e., nouns of happiness) is presented vertically; a horizontal axis covers semes. The size of the matrix of the nouns denoting happiness in English is $102 \times 24$ and its stands can be either filled or empty. Filled stands represent multiaspectual relations among individual lexemes, and empty ones logically mean a zero semantic intersection. A high or low tendency of the observed words to be connected with other words of the field can be deduced from the density of filled stands of a chosen fragment of the matrix.

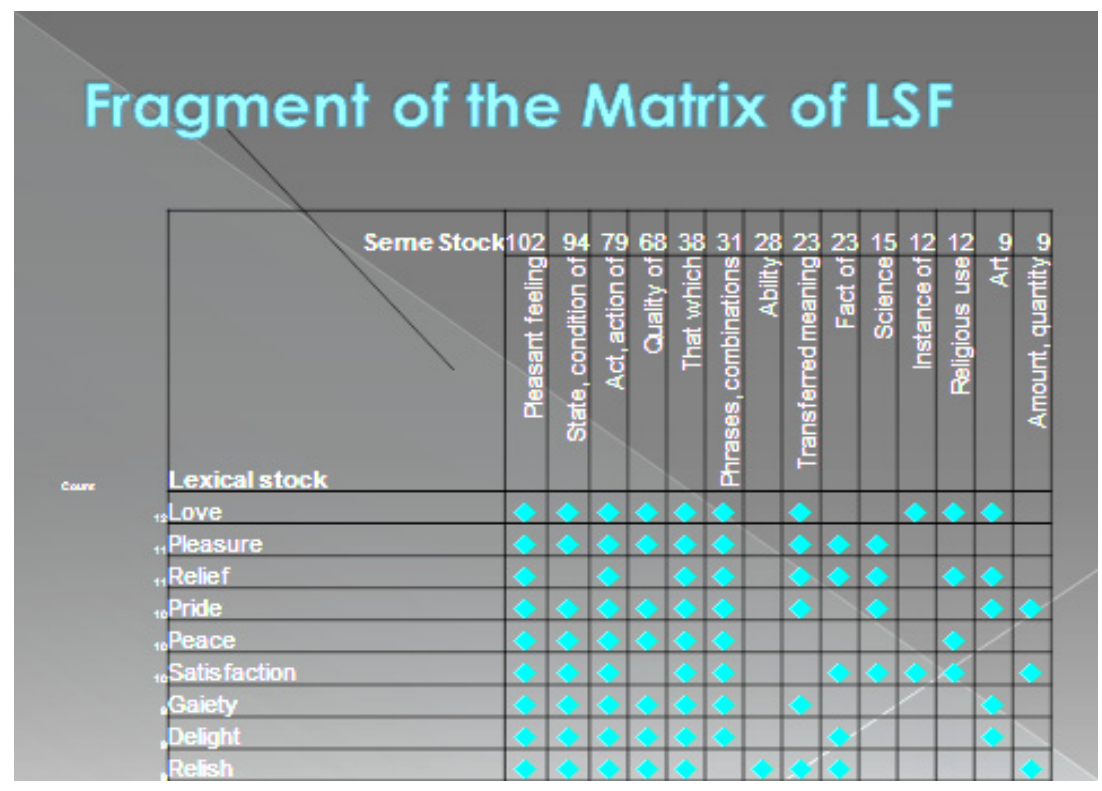

Figure 1. Fragment of the Matrix of LSF of English nouns of happiness.

Matrix analysis is expected to be an effective way of presenting correlations between words and their meanings. Nouns indicating happiness are not only logically arranged in it but they also undergo qualitative and quantitative analyses based on the degree of polysemy of specific nouns and on the frequency of the semes' 
occurrence in the meanings of the nouns.

Another undoubtful advantage of a matrix is that it can be updated whenever it is necessary; its content can be adjusted without the risk of breaking the already created and existing system. As the English vocabulary is in permanent motion, the position of lexemes in it is continuously changed, too. Some of the meanings of the words become obsolete or archaic; others are more popular and colloquial than any time before. A well-constructed matrix helps to react on all these changes. A mathematical method called weighting, by which each element of the seme stock is given different weight, has found its application in this work. The weight of a specific investigated word is given by the sum of weights of its meanings. The more the meaning is to the left side of the horizontal axis, the lower its weight is. That means that if the number or importance of the meanings of a word changes, or even if the word ceases to be important for the research, the matrix can be instantaneously readjusted and the work with the updated data is carried out.

To sum up, it can be pointed out that matrices transparently and economically present not only the nouns' setting environment but also show various aspects of relations between all studied lexemes of the lexical stock of the lexico-semantic field and their meanings, as well as all possible connections with other groups of words and their semantics within a lexico-semantic system of the language under study.

\section{Nouns Denoting Happiness in English}

OTE (the Oxford Thesaurus of English) (2006) offers 45 synonyms of the noun/headword "happiness" (e.g., contentment, pleasure, satisfaction, merriment, etc.). Each of the nouns of the 45-member-synonymic row has its own synonymic row, too (e.g., merriment has got 44 synonyms, pleasure 34, satisfaction 39, and contentment 22 synonyms including happiness). To collect all the synonyms of the noun "happiness" would be therefore a very complicated process without setting a common semantic feature of the observed nouns. We have selected a seme "pleasant feeling" and tried to find it in the meanings of all collected synonyms of the noun "happiness". To make the process simpler, we decided to concentrate on one-word nouns and omit all the archaic, obsolete, dated, historical, offensive, vulgar and slang nouns as well as the nouns not used in British English. At this stage of observation, we consulted also OED (Oxford English Dictionary) (Burchfield, Quirk, \& comp., 2004) for the purpose to find a common semantic feature "pleasant feeling" in the meanings of the nouns under study.

As non-native users of English limited by the contents of both OED and OTE dictionaries, we decided to apply simultaneously also a criterion of a diagnostic frame in order to verify the rightness of our choice ("After spending the evening with her idol Thomas, Becky felt ").

Finally, a set of 102 English nouns of happiness has been collected:

(1) love (12 meanings);

(2) pleasure, relief (11 meanings);

(3) pride, peace, satisfaction (10 meanings);

(4) gaiety, delight, relish, joy, content, heaven (9 meanings);

(5) sunshine, cheer, comfort, felicity, thrill, hope, paradise (8 meanings);

(6) happiness, ease, buoyancy, beatitude, exaltation, rapture, transport (7 meanings);

(7) conviviality, exultation, jocundity, cheerfulness, zest, amusement, excitement, gratification, triumph, complacency, zeal, ecstasy, exuberance (6 meanings);

(8) mirth, optimism, relaxation, blithesomeness, relaxation, fondness, eudemony, exuberance, delectation, 
enchantment, serenity, blessedness, belonging, bliss, glee, enjoyment, exhilaration, liking, contentedness, contentment, peacefulness, lightsomeness, jolliness, joviality, lightheartedness, merriness, blitheness, fulfilment, joyfulness, mirthfulness, élan, jocularity, jollity, enthusiasm (5 meanings);

(9) festivity, sprightliness, liveliness, hilarity, gladsomeness, elation, cheeriness, joyousness, jubilation, gladness, titillation, repletion, blissfulness, chirpiness, sunniness, tranquillity, placidity, joie de vivre, equanimity, carefreeness, restfulness, placidness, pleasance, merriment, ebullience, rejoicing (4 meanings);

(10) ravishment, zestfulness, hopefulness, gleefulness, euphoria (3 meanings).

Table 1

Lexical Stock of English Nouns Denoting Happiness

\begin{tabular}{lclll}
\hline Groups & Lexemes & & Number of meanings & Degree of polysemy \\
\hline I. & 26 & $25.49 \%$ & $12-7$ & High \\
II. & 71 & $69.61 \%$ & $6-4$ & Middle \\
III. & 5 & $5 \%$ & 3 & Low \\
Total & 102 & $100 \%$ & & \\
\hline
\end{tabular}

Lexical stocks of matrices contain synonyms which are interchangeable in some contexts - It is possible to substitute one for another without considerable changing the meaning of the sentence. The identification of synonymy is closely connected with the analysis of the polysemy of lexical items. A polysemantic word can have more different synonyms - Their number depends on the number of different meanings of this word. Complete/absolute/total synonymy is very rare and expressions or words are absolutely synonymous if satisfy the following conditions:

(1) All their meanings are identical;

(2) They are synonymous in all contexts;

(3) They are semantically equivalent on all dimensions of meaning (Lyons, 1995).

Partial/near synonymy concerns the words which are not substitutable in all of their readings. Therefore, when we want to compare near-synonyms, we have to analyse all their meanings and find their common semantic feature(s) and then discuss their connotations as well as ranges of applications.

As regards English nouns denoting feelings and emotions, most of them have both descriptive and expressive meanings. And so, when we want to identify their synonyms, we have to take into consideration the identity of these two types of meanings which cannot be separated one from another. The majority of synonymic and thematic dictionaries contain synonymic rows. Zgusta defines them as chains of near-synonyms in which the adjacent words have a very close meaning, but the terms at the beginning and at the end of the chain have a rather distant meaning (Zgusta, 1971). Synonymic rows can have two or more members which are not semantically equivalent. A dominant (a basic synonym) of a synonymic row is a stylistically neutral lexical unit with the highest frequency of occurrence in a language under study. Lexemes with multiple meanings usually belong to various synonymous rows and may not serve as dominants in all of them.

\section{Componential Analysis}

CA (componential analysis) is a logical development from the lexical field theory as it describes the sense relations among lexemes of a specific field in a formalized, precise and detailed way. By application of this form of analysis, individual meanings of polysemantic words with different componential structure are 
decomposed into the smallest, further unanalysable semantic components-semes. Semes of various levels of abstraction are subsequently hierarchically ordered in a highly structured system. They determine the semantic-syntactic environment of the word and influence the choice of other elements the word will be connected with. Lexical units are studied on the paradigmatic level, i.e., in their relationships with other words of the lexico-semantic field.

CA is founded on the semantic contrast-Lexical units are assumed to contrast simultaneously on different dimensions of meaning or within different semantic systems. Semantic components are in fact contrastive elements essential for the identification of meaning relations. Lounsbury claims that CA presupposes the necessity to look at a set of words in a carefully delineated area, to look at the words which have basic semantic features in common "but whose meanings contrast with each other by virtue of one or more differences in respect to several other features" (Lounsbury, 1956). CA is often used in the process of studying a semantic structure of synonyms. There is always a certain component of meaning which makes one member of the synonymic set different and cannot be found in any other member of this set. CA reveals which components of meaning interconnect and which differentiate the words under study. Speakers are able to categorize, classify, and organize words into semantic fields in many ways, and so the componential analysis can be done in more than one way, too.

If we want to determine componential features of the meaning of a lexical unit, it can be done only by contrasting this meaning with related meanings of other lexical units existing in the same lexico-semantic field. In applying componential analysis to a set of related meanings, it is essential to distinguish between three types of semantic components (Nida, 1975):

(1) common components;

(2) diagnostic components;

(3) supplementary components.

Common components define the whole group as they are common to all the meanings in it. They identify the semantic fields to which the words belong. Diagnostic components distinguish between the various meanings of given words and supplementary components are additional ones which can be important for an extensive definition. A systematic description and arrangement of diagnostic features is done by inserting them into a matrix and using plus-minus distinctions notation.

The seme stock of the nouns denoting happiness in English is made up of 24 semes which were obtained by the method of componential analysis. It was applied on all lexical meanings of the collected nouns. This procedure was justified due to the fact that the meanings of the nouns denoting happiness consisted of the semes by which all the English vocabulary could be described. The semes were put on the horizontal axis of the matrix which became an indispensable device in the process of creating the boundaries between the specific groups of semes. It consists of 2,448 stands/segments which were created by the intersection of lexical and seme stocks of the field. Out of this total number of stands, $579(23.7 \%)$ are filled and indicate common semantics of the lexemes under study (see Figure 1 and Figure 2). 1,869 stands (76.3\%) have remained unfilled/empty so far but the further process of the English vocabulary development will certainly lead to new semantic intersections and subsequent filling of some of them. The reverse process, i.e., disappearance of some words and their meanings and thus disappearance of some intersections and filled stands is inevitable, too.

It is evident from the Matrix of LSF of the nouns denoting happiness in English that different meanings of 
polysemantic nouns have different componential structure and there exists a relation between lexemes and semes which can be notified as $1: x$ for $x>1$ ( $x$ represents the number of semes). The only exception is the case of monosemantic lexemes which are in one-to-one correspondence with the appropriate semes $(x=1)$.

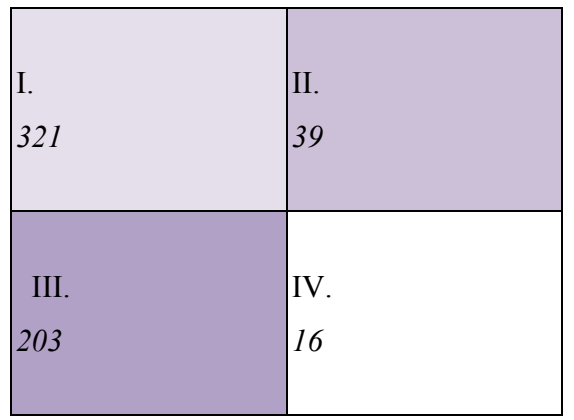

Figure 2. Sectors and filled stands of the Matrix of LSF (simplified version).

\section{Application of Componential Grids in Didactic Practice}

Special componential grids - matrices find their application in the theory and practice of didactics (Anderman \& Rogers, 1996). They can be used as practical teaching aids in the process of vocabulary teaching, learning and acquisition with all the foreign language learners. However, teachers have to take in consideration the language level of their students and choose dictionaries and subsequent learning activities with an appropriate and understandable content and metalanguage.

Since learners tend to recall words according to categories in which they are conceptually mapped, new words should be presented to them not as isolated items but in groups. Grids (matrices) introduce semantically interconnected words which belong to the same semantic field and are subjected to a modified componential analysis. CA is very helpful for teachers as it enables to present sense relations in detail and allows aiming for a precise definition of meaning and considering contrasts of meaning.

With the respect to syllabus as well as the students' needs, a teacher can prepare a grid including needed lexical and semantic data and bring it to the class either in its paper or electronic form (step-by-step drawing of the grid on the board with an active involvement of students is another option). Grid presentation should be discussed in detail either frontally or in groups of students under the teacher's management (Bačová, 2010). Subsequent exercises based on the semantic relations between the words under study (e.g., gap filling and matching exercises, identifying collocational partnerships, etc.) stimulate insightful learning and promote retention of vocabulary in the students' memories.

When students are familiar with the functions of the componential grid, its lexical and semantic stocks and understand the reference of semantic intersections, more advanced activities based on semantic maps can be offered to them. It's time for them to become active participants of the teaching/learning process and apply their language but also creative skills. Students create their own matrices based on the given topic and vocabulary. All of them have to use the same lexicographical sources, i.e. monolingual dictionaries recommended to them. After matrices are checked by the teacher, students can prepare and play games or propose competitions with the swapped matrices from which they will remove semantic intersections, respectively filled segments. The teacher observes, monitors, or directs their activities; his role is to give advice, to consult and arbitrate (Cabanová, 2006). 


\section{Practical Examples}

The major contribution of matrices for linguistic and didactic research and practice is that they enable their users to observe an intersection of the words' meanings and thus indicate common and supplement semes in them. They are also helpful in the process of understanding partial synonymy and nature of synonymic chains.

Semantic overlap among the nouns denoting happiness in English can be demonstrated on the examples of two English nouns bliss and serenity. Both of them have five meanings:

\section{Bliss}

A. Dictionary analysis (OED): 1. blitheness; gladness; joy, delight, enjoyment (1a-physical, social, mundane; $1 \mathrm{~b}$ - mental, ethereal, spiritual: perfect joy or felicity, supreme delight; blessedness; $1 \mathrm{c}$ esp — the perfect joy of heaven; the beatitude of departed souls. Hence, the place of bliss, paradise, heaven; $1 \mathrm{~d}$ concr - a cause of happiness, joy or delight).

B. Componential analysis: pleasant feeling (joy, felicity, delight...); religious use (the perfect joy of heaven...); quality of (quality of being glad...); state, condition of (a state of supreme happiness (blessedness, felicity), state of being glad); that which (a cause of happiness, that which gives pleasure...).

\section{Serenity}

A. Dictionary analysis (OED): 1. clear, fair and calm weather; clearness and stillness of air and sky; 2. (2a-tranquillity, peacefulness; $2 \mathrm{~b}$ - transf. Appearance of reposefulness); 3. Cheerful tranquility (of mind, temper, countenance, etc.); and 4. A title of honour given to reigning princes and other dignitaries.

B. Componential analysis: pleasant feeling (= cheerful tranquillity of mind, ...); transferred meaning (appearance of reposefulness); quality of (quality of being tranquil...); state, condition of (state of being tranquil, calm...); and title (of honour given to reigning princes and...).

Bliss and serenity are characterized by three common semes: "pleasant feeling", "state, condition of", and "quality of". On the other hand, semes "that which" and "religious use" are characteristic only for the meanings of the noun bliss; and "transferred meaning" and "title" can be found only in the meanings of the noun serenity. These semes are characteristic only for one of the compared nouns and are called supplement semes.

Table 2

Common and Supplement Semes of the Nouns "Bliss" and "Serenity"

\begin{tabular}{llllllll}
\hline Seme & Pleasant feeling & State, condition of & Quality of & That which & Religious use & Transf. meaning & Title \\
\hline Bliss & $\mathrm{X}$ & $\mathrm{X}$ & $\mathrm{X}$ & $\mathrm{X}$ & $\mathrm{X}$ & & \\
Serenity & $\mathrm{X}$ & $\mathrm{X}$ & $\mathrm{X}$ & & & $\mathrm{X}$ & $\mathrm{X}$ \\
\hline
\end{tabular}

\section{Practical Activities}

\section{Activity 1: Complete the gaps with the correct noun (bliss or serenity).}

1. The in the aftermath of the tornado was remarkable.

2. Swimming on a hot day is sheer

3. In the manga, Queen first appears in Act 10.

4. Some doctors believe ignorance is and don't give their patients all the facts.

5. The godly life she has lived will surely lead to infinite after death.

6. His calmed those around him.

Activity 1 (Key):

1. serenity; 2. bliss; 3. Serenity; 4. bliss; 5. bliss; 6. serenity; 
Activity 2: In the following sentences one single noun has been removed. Can you deduce it?

1. And the task is even more challenging when you're also trying to maintain privacy and create in a bustling urban area.

2. It, too, is a work of an amazingly precise and thoughtful while evoking the quiet outrage of reason abused.

3. It's a place where the off-kilter meets off-road , where pure spontaneity meets fastidiously manicured fantasy.

4. And when they come home, it should be more a feeling of

Activity 2 (Key): serenity

Activity 3: Read the sentences and find different meanings of the noun bliss.

1. Bliss is accessed more easily when we are able to connect with our feeling states and integrate the spiritual lessons that emotions teach us.

2. I believe everybody deserves a dose of bliss on a daily basis.

3. When I eat the food that I love, I experience true bliss.

4. It is verily a haven of peace and bliss.

5. His songs are full of the divine bliss which he enjoyed and transmitted in abundance.

Activity 3 (Key):

(There are a few possible answers; this is an activity suitable for a group discussion.)

1. Spiritual, perfect joy (state, condition of)

2. Joy, delight (that which)

3. Joy, delight (state, condition of)

4. A place of spiritual joy (religious use)

5. Ethereal joy (that which)

Activity 4: Complete the table using a symbol " $x$ " for semantic intersections, i.e., for common meanings.

\begin{tabular}{|l|l|l|l|l|l|l|l|}
\hline & Pleasant feeling & State, condition of & Quality of & That which & Religious use & Transf. meaning & Title \\
\hline Bliss & & & & & & & \\
\hline Serenity & & & & & & & \\
\hline
\end{tabular}

\section{Conclusion}

Classroom activities based on the componential grids/matrices will provide students with an opportunity to improve the depth of their lexical and semantic knowledge. They are very refreshing, motivating, and inspiring and considerably simplify and fasten the process of storing words in a long-term memory of learners. The reason lies in the fact that language acquisition with the help of "word webs" uses organisation of words similar to mental lexicon arrangement.

Understandably, a teacher has to know how, where and when in the teaching/learning process it would be appropriate to use them. Matrices can be used to facilitate vocabulary learning and review vocabulary lessons. They require rich learning contexts and thoughtful learners with sufficient language level but on the other hand offer endless possibilities for semantic links observations and learning activities preparation.

When working with componential grids and monolingual explanatory dictionaries (or language corpora), learners naturally and gradually get to know also the language picture of the world of the specific language 
bearers which has been determined by historical, social, and cultural development of the nation. Thus, they are indirectly forced to compare it with their own language picture of the world. And this fact cannot be overlooked as young people's perception of intercultural relations during the process of second language acquisition gives another dimension to their education and life itself.

\section{References}

Anderman, G. M., \& Rogers, M. A. (1996). Words, words, words: The translator and the language learner (p. 101). Multilingual Matters.

Bačová, B. (2010). The principle of demonstration-The basic teaching principle. In: XXVIII International Colloquium on the Management of Educational Process (p. 28). Brno: Univerzitaobrany.

Burchfield, R. W., Quirk, R., \& comp. (2004). Oxford English Dictionary (2nd edition on CD-ROM, version 3.1). Oxford: OUP.

Cabanová, V. (2006). Didaktické kompetencie v pregraduálnej príprave učitel’a jazyka. In: Odborová didaktika pri príprave učitel'a materinského a cudzieho jazyka (pp. 271-276). Ružomberok: Katolícká univerzita.

Crystal, D. (2007). Words, words, words (p. 216). Oxford: OUP.

Karris, S. (2004). Numerical analysis: Using MATLAB and spreadsheets (p. 570). Fremont: Orchard Publications.

Lounsbury, F. (1956). A semantic analysis of the Pawnee kinship usage. Language, 37.

Lyons, J. (1995). Linguistic semantics: An introduction (p. 376). Cambridge: CUP.

Nida, E. A. (1975). Language structure and translation (p. 283). Stanford: Stanford University Press.

Oxford Thesaurus of English (2nd revised edition, p. 988). (2006). Oxford: OUP.

Zgusta, L. (1971). Manual of lexicography (p. 357). Praha: Academia. 